\title{
Modeling the mechanics of cancer: effect of changes in cellular and extra-cellular mechanical properties
}

\section{Parag Katira', Roger T. Bonnecaze' and Muhammad H. Zaman ${ }^{2 *}$}

${ }^{1}$ McKetta Department of Chemical Engineering, The University of Texas at Austin, Austin, TX, USA

${ }^{2}$ Department of Biomedical Engineering, Boston University, Boston, MA, USA

\author{
Edited by: \\ Katarzyna Anna Rejniak, H. Lee \\ Moffitt Cancer Center \& Research \\ Institute, USA \\ Reviewed by: \\ Paul Macklin, University of Southern \\ California, USA \\ Yi Jiang, Los Alamos National \\ Laboratory, USA \\ ${ }^{*}$ Correspondence: \\ Muhammad H. Zaman, Department \\ of Biomedical Engineering, Boston \\ University, 38 Cummington Street, \\ Boston, MA 02215, USA \\ e-mail: zaman@bu.edu
}

\begin{abstract}
Malignant transformation, though primarily driven by genetic mutations in cells, is also accompanied by specific changes in cellular and extra-cellular mechanical properties such as stiffness and adhesivity. As the transformed cells grow into tumors, they interact with their surroundings via physical contacts and the application of forces. These forces can lead to changes in the mechanical regulation of cell fate based on the mechanical properties of the cells and their surrounding environment. A comprehensive understanding of cancer progression requires the study of how specific changes in mechanical properties influences collective cell behavior during tumor growth and metastasis. Here we review some key results from computational models describing the effect of changes in cellular and extracellular mechanical properties and identify mechanistic pathways for cancer progression that can be targeted for the prediction, treatment, and prevention of cancer.
\end{abstract}

Keywords: cancer modeling, mechanical forces, cell-material interactions, cell-cell interaction, review

\section{INTRODUCTION}

Cancer is a disease rooted in the dis-regulation of cellular signaling pathways that control cell proliferation and apoptosis. This is generally caused by mutations in genes that express key proteins involved in these biochemical reactions. However, cancer is also accompanied by specific changes in the mechanical properties of cells and their surrounding extra-cellular environment (Figure 1). For example, cancerous cells are less stiff compared to their healthy counter parts (Suresh, 2007). This decrease in cell stiffness with malignant transformation has been observed in a variety of cancers such as breast cancer, lung cancer, renal cancer, prostate cancer, oral cancer, skin cancer, and so on (Guck et al., 2005; Cross et al., 2007; Suresh, 2007; Remmerbach et al., 2009; Fuhrmann et al., 2011; Jonas et al., 2011; Plodinec et al., 2012). Furthermore, the decrease in cell stiffness seems to be greater in cells with higher malignancy and metastatic potential (Swaminathan et al., 2011). Cancerous cells also have increased acto-myosin cortex contractility as compared to corresponding healthy cells (Jonas et al., 2011; Kraning-Rush et al., 2012). This has been observed in response to the stretching of cells by external stimuli. Apart from the cortex stiffness and contractility, cancerous cells also undergo changes in their ability to physically bind to their neighbors and the surrounding extra-cellular elements at different stages of cancer progression (Paredes et al., 2005; Ribeiro et al., 2010a,b). This is caused by the up or down regulation of specific adhesion proteins on the cell surface and affect the growth rate, shape, and invasiveness of tumors. Accompanying the changes in cellular mechanical properties are also some very specific changes in the mechanical properties of the extra-cellular environment. Tumors with high invasive potentials have a stiff extra-cellular environment (Erler and Weaver, 2009; Levental et al., 2009). The tumor extra-cellular environment consists primarily of fibrous tissue made up of collagen fibers. With malignant transformation of cells, an increase in the cross-linking of these fibers and a consequent stiffening of the extra-cellular matrix (ECM) environment has been observed (Erler et al., 2006). Once again this observation is common for a variety of cancers. Also, with the advent of metastasis and the invasion of the extra-cellular environment by cells of a growing tumor, the fibers in the ECM undergo extensive remodeling in terms of degradation, re-polymerization, and alignment (Alini and Losa, 1991; Vijayagopal et al., 1998; Zhang et al., 2003; Yang et al., 2004; Paszek et al., 2005; Vader et al., 2009). This realignment of ECM fibers and strain-induced stretching can alter the ECM mechanical properties as shown by Stein et al. (2011).

There is an increasing interest in the mechanics of cancer progression with an aim to identify mechanistic pathways that can be targeted for the prediction, treatment, and even prevention of cancer. With this in mind it is important to understand the effect of these peculiar changes in cellular and extra-cellular mechanical properties on tumor growth and metastatic potential. The potential influence of mechanical property changes on cell behavior during cancer progression has been discussed in recent commentaries and insight articles (Peyton et al., 2007; Kumar and Weaver, 2009; Fritsch et al., 2010). The underlying idea is that mechanical forces acting on cells can regulate signaling pathways responsible for cell death, division, differentiation, and migration (Assoian and Klein, 2008; Chen, 2008; Mammoto and Ingber, 2009; Nelson and Gleghorn, 2012; West-Foyle and Robinson, 2012). Changes in cellular and extra-cellular mechanical properties during malignant transformation potentially alter the forces acting on cells and thus influence morphogenetic evolution, proliferation, and invasion of cancer cells (Huang and Ingber, 2005; Lopez et al., 2008). It would be desirable to quantify this effect of mechanical properties on collective cell behavior in in vivo and in vitro multi-cellular systems. However, the presence of various other biological factors influencing cell behavior, as well as the complex interplay between 


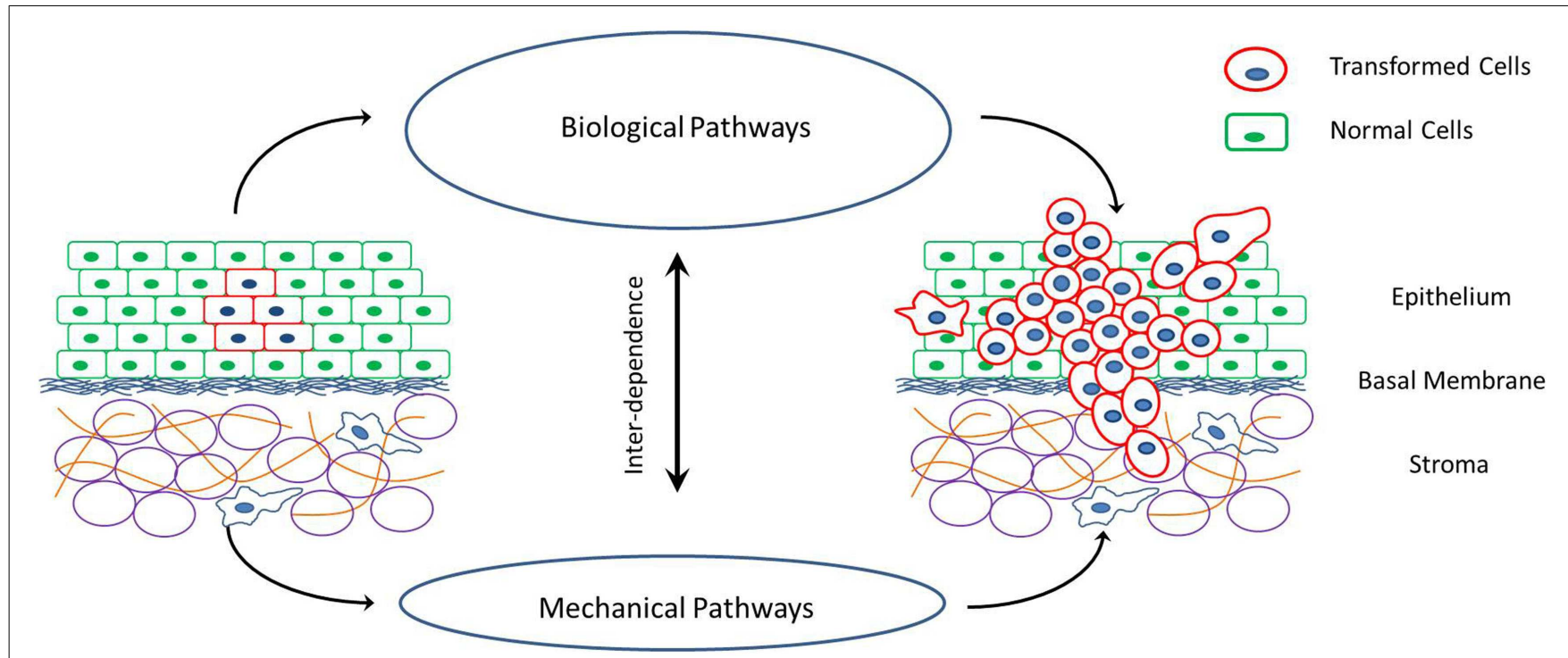

FIGURE 1 | Schematic of cancer progression in a tissue, and the interplay between the mechanical and biological factors that drive these processes of cell proliferation, invasion of surrounding tissue and metastasis via individual or collective cell migration.

the biological and mechanical factors makes it extremely difficult to isolate the effects of mechanical interactions. Computational modeling is an extremely useful tool in such conditions, where the effect of individual parameters can be studied and there is unlimited control on the parameter space.

Computational models can be developed to observe specific effects at various length scales ranging from the molecular to the macroscopic level, and these observations can then be integrated to obtain a complete picture of a specific process. Models have indeed been used extensively in understanding various aspects of cancer progression. Different models focusing on different aspects of cancer, such as effect of genetic heterogeneity, phenotypic evolution, biochemical interactions between cells and their surroundings, chemical and nutrient gradients, external forces, and mechanical interaction between cells, their neighbors, and the ECM can be found in literature. These models vary from being continuum based models of two evolving spatial domains representing the tumor mass and its environment to being discrete models where individual cells interacting with each other and the surroundings describe the system being simulated. A recent trend is to adopt a hybrid approach to incorporate the advantages of both continuum and discrete models into one, with a continuum description for the main tumor mass, and a discrete individual cell approach for tumor-environment interactions. The various modeling approaches have been reviewed in these references (Galle et al., 2006; Sanga et al., 2007; Byrne and Drasdo, 2009; Stolarska et al., 2009; Rejniak and McCawley, 2010; Deisboeck et al., 2011; Frieboes et al., 2011; Kam et al., 2012) and many others. Here we discuss some of these models, and a few other recent ones that examine the role of mechanics in tumor growth and invasion.

The goal of this review is to summarize the effects that changes in mechanical properties of cells and their surroundings have on tumor growth and metastasis as understood from computational models. There are a lot of models that incorporate some form of mechanical interaction between its elements, and many of them are progressions or off-shoots of previous models focusing more on the biochemical aspects of cancer progression. Hence, we shall focus only on key results regarding the influence of mechanical interactions rather than delve into the details of the model development process. With this information, we hope to display the importance of mechanistic models in identifying novel pathways of cancer progression, and direct the reader to more detailed sources on models interesting to them. Table 1 lists the specific changes in cellular and extra-cellular mechanical properties discussed here, experiments describing these changes and the corresponding observations on tumor cell behavior, as well as models that describe potential mechanisms connecting the two.

\section{CHANGES IN EXTRA-CELLULAR MECHANICAL PROPERTIES}

The extra-cellular environment of a carcinoma consists of surrounding healthy cells, a dense layer of fibrous basal membrane, and the surrounding stroma mainly comprised of fibrous matrix, adipocytes, and fibroblasts (Hogg et al., 1983). A growing tumor needs to push against this extra-cellular environment as it grows. Thus, intuitively, the stiffer the extra-cellular environment is, the less it deforms against the pressure applied by the growing tumor, restricting tumor size. This phenomenon was demonstrated experimentally by Helmlinger et al. (1997) and more recently by Cheng et al. (2009). Computationally this has been reproduced with varying levels of agreement by a variety of models (Chen et al., 2001; Ambrosi and Mollica, 2004; Drasdo and Hohme, 2005; Gevertz et al., 2008; Basan et al., 2009; Torquato, 2011; Montel et al., 2012; Ciarletta et al., 2013; Kim and Othmer, 2013) irrespective of model type (continuum, discrete, hybrid) and mechanism (growth retardation by formation of a necrotic core due to lack of nutrients, or by contact inhibition from increased packing density of growing cells, or both). 
Table 1 | Some specific changes in cellular and extra-cellular mechanical properties, observations from experiments and computational models.

Experimental observations

\section{Extra-cellular mechanical properties}

Matrix stiffening (effect of increased density, cross-linking)

(Paszek et al., 2005; Levental et al., 2009)

Matrix re-organization (effect of degradation and realignment) Wolf et al., 2007; Friedl and Wolf, 2008)

\section{Model predictions}

Increased cell proliferation driven by heterogeneity in ECM mechanical properties, protrusions along high density gradients (Macklin and Lowengrub, 2007; Rubenstein and Kaufman, 2008; Anderson et al., 2009; Macklin et al., 2009)

Cell Proliferation driven by matrix degradation through the expression of MMPs and along realigned matrix fibers (Franks et al., 2005; Painter, 2009; Giverso et al., 2010; D'Antonio et al., 2013)

\section{Cellular mechanical properties}

Increase in cell compliance or deformability (Cross et al.,

2007; Fritsch et al., 2010; Jonas et al., 2011)

Changes in cell adhesivity (Paredes et al., 2005; Ribeiro et al., 2010b)

Increase in cell contractility (Jonas et al., 2011; Kraning-Rush et al., 2012) Tumorigenesis and increased malignancy, (Katira et al., 2012). Increased migration through porous ECM (Zaman, 2006; Zaman et al., 2007; Scianna and Preziosi, 2013)

Changes in tumor morphology, growth rates, and metastatic potential (Byrne and Chaplain, 1996; Armstrong et al., 2006; Ramis-Conde et al., 2008b; Frieboes et al., 2010; Rejniak et al., 2010; Katira et al., 2012)

Increased migration rates and rigidity sensing (Moreo et al., 2008; Brodland and Veldhuis, 2012)
However, it is now known that the extra-cellular environment surrounding a tumor stiffens as the cells transform from normal to malignant to metastatic, and this transformation promotes cancer progression rather than arrests it (Paszek et al., 2005; Erler and Weaver, 2009; Klein et al., 2009; Levental et al., 2009; Ulrich et al., 2009). The models described above in their base form do not support this possibility. To explain the growth and metastasis of tumors against a dense, stiff, low porosity extra-cellular environment, models incorporating cell-ECM interactions are required. The continuum model described by Macklin and Lowengrub (2007) suggests that the aggressiveness of tumors growing in denser, stiffer environments that restrict cell mobility arises from increased shape instabilities during tumor growth and the formation of invasive finger-like morphologies. On the other hand, Franks et al. (2005) have suggested that tumor growth in a harsh environment like the one described above can lead to cell morphogenesis and progression toward a more malignant phenotype expressing high level of matrix degrading proteins (MMPs). These MMPs can then degrade the stiff, cross-linked ECM, weakening it. The growing tumor can then push against these weaker sections to grow as shown by D'Antonio et al. (2013). Chaplain et al. (2006) also incorporate a more active role of cell-ECM interactions in altering cell proliferation and migration rates to explain the growth of solid tumors against stiff extra-cellular environments. Their model focuses solely on mechanistic factors influencing tumor growth and incorporates the increase in ECM fiber density (Christensen, 1992; Kauppila et al., 1998; Brown et al., 1999) as well as changes in ECM degradation rates observed with malignant transformation (Clark et al., 2007; Alexander et al., 2008; Rizki et al., 2008). Increased ECM density facilitates cell proliferation as well as cell migration up to a certain extent (Zaman et al., 2006; Alexander et al., 2008). Increased MMP activity and corresponding degradation of the ECM also promotes cell migration through a dense ECM up to a certain extent (Erler and Weaver, 2009; Harjanto and Zaman, 2010). The effect of ECM density and cross-linking on cell invasiveness via the formation of invadopodia has been computationally modeled by Enderling et al. (2008). The effect of ECM degradation via the action of MMPs and resulting cell invasion has been modeled by Giverso et al. (2010). Based on the balance between the ECM fiber deposition and MMP degradation rates, as well as the spatial distribution of these factors in the tissue, various regimes of tumor growth, arrest, and invasion are possible. The heterogeneity arising in the tissue environment in terms of ECM density and stiffness because of these interactions can give rise to different morphologies for a growing tumor (Anderson et al., 2006; Frieboes et al., 2007; Gerlee and Anderson, 2008; Macklin and Lowengrub, 2008; Macklin et al., 2009; Trucu et al., 2013). Another model useful for studying the effect of ECM structure is described by Rubenstein and Kaufman (2008) where cell fate decisions are influenced by the neighboring elements and the overall interaction energy of the multi-cellular system. This allows for cell-cell as well as cell-ECM interactions to influence cell behavior and different collective phenomena can be observed based on the interaction rules. The model shows similar results as the described above, with increased cell proliferation near the densest ECM regions. Apart from cell proliferation and increased motility, changes in ECM structure can also impart directionality to the cells emanating from a growing tumor as shown computationally by Painter (2009). This is made possible through a mechanism know as contact guidance (Dunn and Heath, 1976; Guido and Tranquillo, 1993) where cells migrate along the length of ECM fibers. Thus, formation of aligned ECM fiber bundles can influence directed cell motility into the surrounding tissue.

\section{CHANGES IN CELLULAR MECHANICAL PROPERTIES}

Cells undergo very specific changes in their mechanical properties along with malignant transformation, just as the extra-cellular environment does. One particular change is the decrease in the stiffness of cells, or in other words, an increase in the compliance or deformability of cells. This has been observed for many 
different cancers. Furthermore, increased deformability of cells corresponds to higher malignancy and metastatic potential. This change in the mechanical property of cells complements that of the extra-cellular environment, which gets stiffer with increased malignancy. Using computational modeling Katira et al. (2012) have shown that decrease in cell stiffness can have a similar effect on cell proliferation rates as increase in the stiffness of the surroundings do (Klein et al., 2009). The model by Katira et al. incorporates the mechanical regulation of cell fate driven by changes in cell shape, and suggests that for cell clusters larger than a threshold size, the decrease in cell stiffness can drive uncontrolled growth and evasion of apoptosis in cells. While there are a number of other factors that influence cell proliferation, this seems to be a mechanistic pathway that aids tumor growth. The effect of changes in cell stiffness has also been studied by Drasdo and Hoehme (2012), where they look at the mechanical interactions between cells and a granular surrounding medium. Apart from tumor growth, the decrease in stiffness of cells has been shown to influence their ability to navigate tight turns during cell migration (Park et al., 2005; Lautenschlager et al., 2009). While the effect of this on cell migration during metastasis through the ECM is unknown, a potential increase in mobility can be predicted based on the models described in (Zaman et al., 2007; Scianna and Preziosi, 2013).

Apart from the lowering of cell stiffness, cells undergo changes in their binding ability with other cancer cells, normal cells, and the extra-cellular environment. These changes vary with cell phenotype and can be different at different stages of cancer progression. Also, their effects on tumor growth can vary based on the size and morphology of the tumor and the tumor-environment. For example studies have shown increased malignancy but non-invasiveness in tumors with increased P-cadherin binding between the cells (Van Marck et al., 2005). On the other hand studies have shown tumor growth arrest with increased E-cadherin binding. Other results have also shown increase in malignancy with decreased Ecadherin mediated adhesion (Bryan et al., 2008), while in still other cases the initiation of metastasis is driven by hypoxia induced loss of binding (Behrens et al., 1989; Finger and Giaccia, 2010). The effect of changes in cell adhesion has been studied in a lot of different modeling works (Drasdo and Hohme, 2005; Armstrong et al., 2006; Anderson et al., 2009; Bearer et al., 2009; Frieboes et al., 2010; Katira et al., 2012). One of the early models describing the effect of cell-cell adhesion on tumor growth is by Byrne and Chaplain (1996). The model balances the internal pressure of a growing tumor to the surface tension which is a function of the cell-cell adhesion. Thus changes in adhesion energies can drive

\section{REFERENCES}

Alexander, N. R., Branch, K. M., Parekh, A., Clark, E. S., Lwueke, L. C., Guelcher, S. A., et al. (2008). Extracellular matrix rigidity promotes invadopodia activity. Curr. Biol. 18, 1295-1299. doi:10.1016/j.cub.2008.07.090

Alini, M., and Losa, G. A. (1991). Partial characterization of proteoglycans isolated from neoplastic and nonneoplastic human breast tissues. Cancer Res. 51, 1443-1447.

Ambrosi, D., and Mollica, F. (2004). The role of stress in the growth of a multicell spheroid. J. Math. Biol. 48, 477-499. doi:10.1007/s00285003-0238-2

Anderson, A. R. A., Rejniak, K. A., Gerlee, P., and Quaranta, V. (2009). Microenvironment driven invasion: a multiscale multimodel

instabilities in the contour profile of the growing tumor and result in finger-like extensions, representing metastasis. A model specifically suited for analyzing the effect of multiple changes occurring in the expression of cell-surface proteins that regulate cell-cell and cell-ECM interactions is the IBCell model described by Rejniak et al. (2010). The model describes cell behavior in terms of growth, phenotypic evolution, and apoptosis as a function of all the interactions it has with its neighbors and the different levels of surface proteins it is expressing at the time. This enables the prediction of a variety of different phenomena arising during malignant transformation and tumor growth. In principal this model is similar to the Rubenstein model mentioned previously, however the focused application described has been on the effect of changes in expressed cell-surface receptors and mechanical interactions between cells. Ramis-Conde et al. (2008a,b) describe a slightly different model focusing on the cadherin-catenin biochemical pathway and its effect on mechanical interaction between cells. The detachment of the cadherin bonds triggers the wnt-signaling pathway, and the model is able to predict epithelial to mesenchymal transition and cell migration toward a particular signal source.

\section{FUTURE DIRECTIONS}

There are a number of models that describe the mechanics of cancer and the effect of specific changes in cellular and extra-cellular properties. However, it is necessary to combine these models focusing on different aspects of cell-cell and cell-ECM mechanical interactions into a unified theory of cancer progression. This comprehensive understanding of all the mechanical aspects is required in order to predict clinically observed tumor growth and metastasis, and decouple the mechanics from the biology. The idea that a select few changes in cellular and extra-cellular mechanical properties can promote the growth of a malignant phenotype of cancer is intriguing. As depicted in Figure 1, there is a strong interplay between biological and mechanical factors involved in cancer progression, with each one influencing the other. This opens up the possibility of mechanical regulation and manipulation of cell behavior to alter cancer outcome. Researchers can develop tools to predict and treat cancer that are focused on rectifying the few mechanical property changes (for examples refer to Lekka et al., 2001; Cross et al., 2011) as compared to vast number of heterogeneous genetic and epigenetic factors associated with cancer progression (Swanton et al., 2011; Visvader, 2011).

\section{ACKNOWLEDGMENTS}

The authors would like to acknowledge the support from National Institutes of Health (R01CA132633) to Muhammad H. Zaman.

investigation. J. Math. Biol. 58, 579-624. doi:10.1007/s00285-0080210-2

Anderson, A. R. A., Weaver, A. M., Cummings, P. T., and Quaranta, V. (2006). Tumor morphology and phenotypic evolution driven by selective pressure from the microenvironment. Cell 127 , 905-915. doi:10.1016/j.cell.2006. 09.042
Armstrong, N. J., Painter, K. J., and Sherratt, J. A. (2006). A continuum approach to modelling cell-cell adhesion. J. Theor. Biol. 243, 98-113. doi:10.1016/j.jtbi.2006.05.030

Assoian, R. K., and Klein, E. A (2008). Growth control by intracellular tension and extracellular stiffness. Trends Cell Biol. 18, 347-352. doi:10.1016/j.tcb.2008. 05.002 
Basan, M., Risler, T., Joanny, J. F., Sastre-Garau, X., and Prost, J. (2009). Homeostatic competition drives tumor growth and metastasis nucleation. HFSP J. 3, 265-272. doi:10.2976/1.3086732

Bearer, E. L., Lowengrub, J. S., Frieboes, H. B., Chuang, Y. L., Jin, F., Wise, S. M., et al. (2009). Multiparameter computational modeling of tumor invasion. Cancer Res. 69, 4493-4501. doi:10.1158/00085472.CAN-08-3834

Behrens, J., Mareel, M. M., Vanroy, F. M., and Birchmeier, W. (1989). Dissecting tumorcell invasion - epithelial-cells acquire invasive properties after the loss of uvomorulinmediated cell cell-adhesion. J. Cell Biol. 108, 2435-2447. doi:10.1083/jcb.108.6.2435

Brodland, G. W., and Veldhuis, J. H. (2012). The mechanics of metastasis: insights from a computational model. PLoS ONE 7:e44281. doi:10.1371/journal.pone.0044281

Brown, L. F., Guidi, A. J., Schnitt, S. J., Van De Water, L., Iruela-Arispe, M. L., Yeo, T. K., et al. (1999). Vascular stroma formation in carcinoma in situ, invasive carcinoma, and metastatic carcinoma of the breast. Clin. Cancer Res. 5, 1041-1056.

Bryan, R. T., Atherfold, P. A., Yeo, Y., Jones, L. J., Harrison, R. F., Wallace, D. M. A., et al. (2008). Cadherin switching dictates the biology of transitional cell carcinoma of the bladder: ex vivo and in vitro studies. J. Pathol. 215, 184-194. doi:10.1002/path.2346

Byrne, H., and Drasdo, D. (2009). Individual-based and continuum models of growing cell populations: a comparison. J. Math. Biol. 58, 657-687. doi:10.1007/s00285008-0212-0

Byrne, H. M., and Chaplain, M. A. J. (1996). Modelling the role of cell-cell adhesion in the growth and development of carcinoma. Math. Comput. Model 24, 1-17. doi:10.1016/S08957177(96)00174-4

Chaplain, M. A. J., Graziano, L., and Preziosi, L. (2006). Mathematical modelling of the loss of tissue compression responsiveness and its role in solid tumour development. Math. Med. Biol. 23, 197-229. doi:10.1093/imammb/dql009

Chen, C. S. (2008). Mechanotransduction - a field pulling together? J. Cell. Sci. 121, 3285-3292. doi:10.1242/jcs.023507

Chen, C. Y., Byrne, H. M., and King, J. R. (2001). The influence of growth-induced stress from the surrounding medium on the development of multicell spheroids. J. Math. Biol. 43, 191-220. doi:10.1007/s002850100091

Cheng, G., Tse, J., Jain, R. K., and Munn, L. L. (2009). Microenvironmental mechanical stress controls tumor spheroid size and morphology by suppressing proliferation and inducing apoptosis in cancer cells. PLoS ONE 4:e4632. doi:10.1371/journal.pone.0004632

Christensen, L. (1992). The distribution of fibronectin, laminin and tetranectin in human breastcancer with special attention to the extracellular-matrix. APMIS 100, 1-39.

Ciarletta, P., Ambrosi, D., Maugin, G. A., and Preziosi, L. (2013). Mechanotransduction in tumour growth modelling. Eur. Phys. J. E Soft Matter 36, 1-9. doi:10.1140/epje/i201313023-2

Clark, E. S., Whigham, A. S., Yarbrough, W. G., and Weaver, A. M. (2007). Cortactin is an essential regulator of matrix metalloproteinase secretion and extracellular matrix degradation in invadopodia. Cancer Res. 67, 4227-4235. doi:10.1158/00085472.CAN-06-3928

Cross, S. E., Jin, Y. S., Lu, Q. Y., Rao, J. Y., and Gimzewski, J. K. (2011). Green tea extract selectively targets nanomechanics of live metastatic cancer cells. Nanotechnology 22, doi:10.1088/09574484/22/21/215101

Cross, S. E., Jin, Y. S., Rao, J., and Gimzewski, J. K. (2007). Nanomechanical analysis of cells from cancer patients. Nat. Nanotechnol. 2, 780-783. doi:10.1038/nnano. 2007.388

D’Antonio, G., Macklin, P., and Preziosi, L. (2013). An agent-based model for elasto-plastic mechanical interactions between cells, basement membrane and extracellular matrix. Math. Biosci. Eng. 10, 75-101. doi:10.3934/mbe.2013.10.75

Deisboeck, T. S., Wang, Z. H., Macklin, P., and Cristini, V. (2011). Multiscale cancer modeling. Annu. Rev. Biomed. Eng. 13, 127-155. doi:10.1146/annurev-bioeng071910-124729

Drasdo, D., and Hoehme, S. (2012). Modeling the impact of granular embedding media, and pulling versus pushing cells on growing cell clones. New J. Phys. 14:055025. doi:10.1088/13672630/14/5/055025

Drasdo, D., and Hohme, S. (2005). A single-cell-based model of tumor growth in vitro: monolayers and spheroids. Phys. Biol. 2, 133-147. doi:10.1088/1478-3975/2/3/001

Dunn, G. A., and Heath, J. P. (1976). New hypothesis of contact guidance in tissue-cells. Exp. Cell Res. 101, 1-14. doi:10.1016/00144827(76)90405-5

Enderling, H., Alexander, N. R., Clark, E. S., Branch, K. M., Estrada, L., Crooke, C., et al. (2008). Dependence of invadopodia function on collagen fiber spacing and cross-linking: computational modeling and experimental evidence. Biophys. J. 95, 2203-2218. doi:10.1529/biophysj.108.133199

Erler, J. T., Bennewith, K. L., and Giaccia, A. J. (2006). The role of lysyl oxidase in premetastatic niche formation. Breast Cancer Res. Treat. 100, S7-S7.

Erler, J. T., and Weaver, V. M. (2009). Three-dimensional context regulation of metastasis. Clin. Exp. Metastasis 26, 35-49. doi:10.1007/s10585008-9209-8

Finger, E. C., and Giaccia, A. J. (2010). Hypoxia, inflammation, and the tumor microenvironment in metastatic disease. Cancer Metastasis Rev. 29, 285-293. doi:10.1007/s10555-010-9224-5

Franks, S. J., Byrne, H. M., Underwood, J. C. E., and Lewis, C. E. (2005). Biological inferences from a mathematical model of comedo ductal carcinoma in situ of the breast. J. Theor. Biol. 232, 523-543. doi:10.1016/j.jtbi.2004.08.032

Frieboes, H. B., Chaplain, M. A. J., Thompson, A. M., Bearer, E. L., Lowengrub, J. S., and Cristini, V. (2011). Physical oncology: a bench-to-bedside quantitative and predictive approach. Cancer Res. 71, 298-302. doi:10.1158/00085472.CAN-10-2676

Frieboes, H. B., Jin, F., Chuang, Y. L., Wise, S. M., Lowengrub, J. S., and Cristini, V. (2010). Three-dimensional multispecies nonlinear tumor growth-II: tumor invasion and angiogenesis. $J$. Theor. Biol. 264, 1254-1278. doi:10.1016/j.jtbi.2010.02.036

Frieboes, H. B., Lowengrub, J. S., Wise, S., Zheng, X., Macklin, P., Elaine, L. B. D., et al. (2007). Computer simulation of glioma growth and morphology. Neuroimage 37, S59-S70. doi:10.1016/ j.neuroimage.2007.03.008

Friedl, P., and Wolf, K. (2008). Tube travel: the role of proteases in individual and collective a cancer cell invasion. Cancer Res. 68, 7247-7249. doi:10.1158/00085472.CAN-08-0784
Fritsch, A., Hockel, M., Kiessling, T., Nnetu, K. D., Wetzel, F., Zink, M., et al. (2010). Are biomechanical changes necessary for tumour progression? Nat. Phys. 6, 730-732. doi:10.1038/nphys1800

Fuhrmann, A., Staunton, J. R., Nandakumar, V., Banyai, N., Davies, P. C. W., and Ros, R. (2011). AFM stiffness nanotomography of normal, metaplastic and dysplastic human esophageal cells. Phys. Biol. 8:015007. doi:10.1088/14783975/8/1/015007

Galle, J., Aust, G., Schaller, G., Beyer, T., and Drasdo, D. (2006). Individual cell-based models of the spatialtemporal organization of multicellular systems - achievements and limitations. Cytometry A 69A, 704-710. doi:10.1002/cyto.a.20287

Gerlee, P., and Anderson, A. R. A. (2008). A hybrid cellular automaton model of clonal evolution in cancer: the emergence of the glycolytic phenotype. J. Theor. Biol. 250, 705-722. doi:10.1016/j.jtbi.2007.10.038

Gevertz, J. L., Gillies, G. T., and Torquato, S. (2008). Simulating tumor growth in confined heterogeneous environments. Phys. Biol. 5, 036010. doi:10.1088/1478-3975/5/3/036010

Giverso, C., Scianna, M., Preziosi, L., Lo Buono, N., and Funaro, A. (2010). Individual cell-based model for in-vitro mesothelial invasion of ovarian cancer. Math Model. Nat. Phenom. 5, 203-223. doi:10.1051/mmnp/20105109

Guck, J., Schinkinger, S., Lincoln, B., Wottawah, F., Ebert, S., Romeyke, M., et al. (2005). Optical deformability as an inherent cell marker for testing malignant transformation and metastatic competence. Biophys. J. 88, 3689-3698. doi:10.1529/biophysj.104.045476

Guido, S., and Tranquillo, R. T. (1993). A methodology for the systematic and quantitative study of cell contact guidance in oriented collagen gels correlation of fibroblast orientation and gel birefringence. J. Cell. Sci. 105 , 317-331.

Harjanto, D., and Zaman, M. H. (2010). Computational study of proteolysis-driven single cell migration in a three-dimensional matrix. Ann. Biomed. Eng. 38, 1815-1825. doi:10.1007/s10439010-9970-0

Helmlinger, G., Netti, P. A., Lichtenbeld, H. C., Melder, R. J., and Jain, R. K. (1997). Solid stress inhibits the growth of multicellular tumor spheroids. Nat. Biotechnol. 15, 778-783. doi:10.1038/nbt0897-778 
Hogg, N. A. S., Harrison, C. J., and Tickle, C. (1983). Lumen formation in the developing mouse mammarygland. J. Embryol. Exp. Morphol. 73, 39-57.

Huang, S., and Ingber, D. E. (2005). Cell tension, matrix mechanics, and cancer development. Cancer Cell 8, 175-176. doi:10.1016/j.ccr.2005.08.009

Jonas, O., Mierke, C. T., and Kas, J. A. (2011). Invasive cancer cell lines exhibit biomechanical properties that are distinct from their noninvasive counterparts. Soft Matter 7, 11488-11495. doi:10.1039/clsm05532a

Kam, Y., Rejniak, K. A., and Anderson, A. R. A. (2012). Cellular modeling of cancer invasion: integration of in silico and in vitro approaches. J. Cell. Physiol. 227, 431-438. doi:10.1002/ jcp.22766

Katira, P., Zaman, M. H., and Bonnecaze, R. T. (2012). How changes in cell mechanical properties induce cancerous behaviour. Phys. Rev. Lett. 108:028103. doi:10.1103/ PhysRevLett.108.028103

Kauppila, S., Stenback, F., Risteli, J., Jukkola, A., and Risteli, L. (1998). Aberrant type I and type III collagen gene expression in human breast cancer in vivo. J. Pathol. 186, 262-268. doi:10.1002/(SICI) 10969896(1998110) 186:3<262::AID-

PATH191>3.0.CO;2-3

Kim, Y., and Othmer, H. G. (2013). A hybrid model of tumor-stromal interactions in breast cancer. Bull. Math. Biol. doi:10.1007/s11538-0129787-0. [Epub ahead of print].

Klein, E. A., Yin, L. Q., Kothapalli, D., Castagnino, P., Byfield, F. J., Xu, T. N., et al. (2009). Cell-cycle control by physiological matrix elasticity and in vivo tissue stiffening. Curr. Biol. 19, 1511-1518. doi:10.1016/j.cub.2009. 07.069

Kraning-Rush, C. M., Califano, J. P., and Reinhart-King, C. A. (2012). Cellular traction stresses increase with increasing metastatic potential. PLoS ONE 7:e32572. doi:10.1371/journal.pone.0032572

Kumar, S., and Weaver, V. (2009). Mechanics, malignancy, and metastasis: the force journey of a tumor cell. Cancer Metastasis Rev. 28, 113-127. doi:10.1007/s10555-0089173-4

Lautenschlager, F., Paschke, S., Schinkinger, S., Bruel, A., Beil, M., and Guck, J. (2009). The regulatory role of cell mechanics for migration of differentiating myeloid cells. Proc. Natl. Acad.
Sci. U.S.A. 106, 15696-15701. doi:10.1073/pnas.0811261106

Lekka, M., Laidler, P., Ignacak, J., Labedz, M., Lekki, J., Struszczyk, H., et al. (2001). The effect of chitosan on stiffness and glycolytic activity of human bladder cells. Biochim. Biophys. Acta 1540, 127-136. doi:10.1016/S01674889(01)00125-2

Levental, K. R., Yu, H. M., Kass, L., Lakins, J. N., Egeblad, M., Erler, J. T., et al. (2009). Matrix crosslinking forces tumor progression by enhancing integrin signaling. Cell 139, 891-906. doi:10.1016/j.cell.2009.10.027

Lopez, J. I., Mouw, J. K., and Weaver, V. M. (2008). Biomechanical regulation of cell orientation and fate. Oncogene 27, 6981-6993. doi:10.1038/onc.2008.348

Macklin, P., and Lowengrub, J. (2007). Nonlinear simulation of the effect of microenvironment on tumor growth. J. Theor. Biol. 245, 677-704. doi:10.1016/j.jtbi.2006.12.004

Macklin, P., and Lowengrub, J. S. (2008). A new ghost cell/level set method for moving boundary problems: application to tumor growth. J. Sci. Comput. 35, 266-299. doi:10.1007/s10915-008-9190-z

Macklin, P., McDougall, S., Anderson, A. R. A., Chaplain, M. A. J., Cristini, V., and Lowengrub, J. (2009). Multiscale modelling and nonlinear simulation of vascular tumour growth. J. Math. Biol. 58, 765-798. doi:10.1007/ s00285-008-0216-9

Mammoto, A., and Ingber, D. E. (2009). Cytoskeletal control of growth and cell fate switching. Curr. Opin. Cell Biol. 21, 864-870. doi:10.1016/j.ceb.2009.08.001

Montel, F., Delarue, M., Elgeti, J., Vignjevic, D., Cappello, G., and Prost, J. (2012). Isotropic stress reduces cell proliferation in tumor spheroids. New J. Phys. 14:055008. doi:10.1088/13672630/14/5/055008

Moreo, P., Garcia-Aznar, J. M., and Doblare, M. (2008). Modeling mechanosensing and its effect on the migration and proliferation of adherent cells. Acta Biomater. 4, 613-621. doi:10.1016/j.actbio.2007.10.014

Nelson, C. M., and Gleghorn, J. P. (2012). Sculpting organs: mechanical regulation of tissue development. Annu. Rev. Biomed. Eng. 14, 129-154. doi:10.1146/annurevbioeng-071811-150043

Painter, K. J. (2009). Modelling cell migration strategies in the extracellular matrix. J. Math. Biol. 58,
511-543. doi:10.1007/s00285-0080217-8

Paredes, J., Albergaria, A., Oliveira J. T., Jeronimo, C., Milanezi, F., and Schmitt, F. C. (2005). Pcadherin overexpression is an indicator of clinical outcome in invasive breast carcinomas and is associated with $\mathrm{CDH} 3$ promoter hypomethylation. Clin. Cancer Res. 11, 5869-5877. doi:10.1158/10780432.CCR-05-0059

Park, S., Koch, D., Cardenas, R., Kas, J., and Shih, C. K. (2005) Cell motility and local viscoelasticity of fibroblasts. Biophys. J. 89, 4330-4342. doi:10.1529/ biophysj.104.053462

Paszek, M. J., Zahir, N., Johnson, K. R., Lakins, J. N., Rozenberg, G. I., Gefen, A., et al. (2005). Tensional homeostasis and the malignant phenotype. Cancer Cell 8, 241-254. doi:10.1016/j.ccr.2005.08.010

Peyton, S. R., Ghajar, C. M., Khatiwala, C. B., and Putnam, A. J. (2007). The emergence of ECM mechanics and cytoskeletal tension as important regulators of cell function. Cell Biochem. Biophys. 47, 300-320. doi:10.1007/ s12013-007-0004-y

Plodinec, M., Loparic, M., Monnier, C. A., Obermann, E. C. Zanetti-Dallenbach, R., Oertle, P., et al. (2012). The nanomechanical signature of breast cancer. Nat. Nanotechnol. 7, 757-765. doi:10.1038/nnano.2012.167

Ramis-Conde, I., Chaplain, M. A. J., and Anderson, A. R. A. (2008a). Mathematical modelling of cancer cell invasion of tissue. Math Comput. Model 47, 533-545. doi:10.1016/j.mcm.2007.02.034

Ramis-Conde, I., Drasdo, D., Anderson, A. R. A., and Chaplain, M. A. J. (2008b). Modeling the influence of the E-cadherinbeta-catenin pathway in cancer cell invasion: a multiscale approach. Biophys. J. 95, 155-165. doi:10.1529/biophysj.107.114678

Rejniak, K. A., and McCawley, L. J. (2010). Current trends in mathematical modeling of tumormicroenvironment interactions: a survey of tools and applications. Exp. Biol. Med. 235, 411-423. doi:10.1258/ebm.2009.009230

Rejniak, K. A., Wang, S. Z. E., Bryce, N. S., Chang, H., Parvin, B., Jourquin, J., et al. (2010). Linking changes in epithelial morphogenesis to cancer mutations using computational modeling. PLoS Comput. Biol. 6:e1000900 doi:10.1371/journal.pcbi.1000900
Remmerbach, T. W., Wottawah, F., Dietrich, J., Lincoln, B., Wittekind, C., and Guck, J. (2009). Oral cancer diagnosis by mechanical phenotyping. Cancer Res. 69, 1728-1732. doi:10. 1158/0008-5472.CAN-08-4073

Ribeiro, A. S., Albergaria, A., Sousa, B., Correia, A. L., Bracke, M., Seruca, R., et al. (2010a). Extracellular cleavage and shedding of P-cadherin: a mechanism underlying the invasive behaviour of breast cancer cells. Oncogene 29, 392-402. doi:10.1038/onc.2009.338

Ribeiro, A. S., Carreto, L. C., Albergaria, A., Sousa, B., Ricardo, S., Milanezi, F., et al. (2010b). Co-expression of E- and P-cadherin in breast cancer: role as an invasion suppressor or as an invasion promoter? EJC Suppl. 8, 131-132.

Rizki, A., Weaver, V. M., Lee, S. Y., Rozenberg, G. I., Chin, K., Myers, C. A., et al. (2008). A human breast cell model of preinvasive to invasive transition. Cancer Res 68, 1378-1387. doi:10.1158/00085472.CAN-07-2225

Rubenstein, B. M., and Kaufman, L. J. (2008). The role of extracellular matrix in glioma invasion: a cellular Potts model approach. Biophys. J. 95, 5661-5680. doi:10.1529/biophysj.108.140624

Sanga, S., Frieboes, H. B., Zheng, X. M., Gatenby, R., Bearer, E. L., and Cristini, V. (2007). Predictive oncology: a review of multidisciplinary, multiscale in silico modeling linking phenotype, morphology and growth. Neuroimage 37, S120-S134. doi:10.1016/j.neuroimage.2007.05. 043

Scianna, M., and Preziosi, L. (2013). Modeling the influence of nucleus elasticity on cell invasion in fiber networks and microchannels. J. Theor. Biol. 317, 394-406. doi:10.1016/j.jtbi.2012.11.003

Stein, A. M., Vader, D. A., Weitz, D. A. and Sander, L. M. (2011). The micromechanics of three-dimensional collagen-I gels. Complexity 16 , 22-28. doi:10.1002/cplx.20332

Stolarska, M. A., Kim, Y., and Othmer, H. G. (2009). Multiscale models of cell and tissue dynamics. Philos. Trans. A Math Phys. Eng. Sci. 367, 3525-3553. doi:10.1098/rsta.2009.0095

Suresh, S. (2007). Biomechanics and biophysics of cancer cells. Acta Mater. 55, 3989-4014. doi:10.1016/j.actamat.2007.04.022

Swaminathan, V., Mythreye, K., O'Brien, E. T., Berchuck, A., Blobe, G. C., and Superfine, R. (2011). Mechanical 
stiffness grades metastatic potential in patient tumor cells and in cancer cell lines. Cancer Res. 71, 5075-5080. doi:10.1158/00085472.CAN-11-0247

Swanton, C., Burrell, R. A., and Futreal, P. A. (2011). Breast cancer genome heterogeneity: a challenge to personalised medicine? Breast Cancer Res. 13, 104-105. doi:10.1186/ bcr 2807

Torquato, S. (2011). Toward an Ising model of cancer and beyond. Phys. Biol. 8, 015017. doi:10.1088/14783975/8/1/015017

Trucu, D., Lin, P., Chaplain, M. A. J., and Wang, Y. (2013). A multiscale moving boundary model arising in cancer invasion. Multiscale Model. Simul. 11, 309-335. doi:10.1137/110839011

Ulrich, T. A., Pardo, E. M. D., and Kumar, S. (2009). The mechanical rigidity of the extracellular matrix regulates the structure, motility, and proliferation of glioma cells. Cancer Res. 69, 4167-4174. doi:10. 1158/0008-5472.CAN-08-4859

Vader, D., Kabla, A., Weitz, D., and Mahadevan, L. (2009). Strain-induced alignment in collagen gels. PLoS ONE 4:e5902. doi:10.1371/journal.pone.0005902
Van Marck, V., Stove, C., Van Den Bossche, K., Stove, V., Paredes, J., Haeghen, Y. V., et al. (2005). P-cadherin promotes cell-cell adhesion and counteracts invasion in human melanoma. Cancer Res. 65, 8774-8783. doi:10.1158/00085472.CAN-04-4414

Vijayagopal, P., Figueroa, J. E., and Levine, E. A. (1998). Altered composition and increased endothelial cell proliferative activity of proteoglycans isolated from breast carcinoma. J. Surg. Oncol. 68, 250-254. doi:10.1002/(SICI)10969098(199808)68:4<250::AIDJSO9>3.3.CO;2-9

Visvader, J. E. (2011). Cells of origin in cancer. Nature 469, 314-322. doi:10.1038/ nature09781

West-Foyle, H., and Robinson, D. N. (2012). Cytokinesis mechanics and mechanosensing. Cytoskeleton (Hoboken) 69, 700-709. doi: $10.1002 / \mathrm{cm} .21045$

Wolf, K., Wu, Y. I., Liu, Y., Geiger, J., Tam, E., Overall, C., et al. (2007). Multistep pericellular proteolysis controls the transition from individual to collective cancer cell invasion. Nat. Cell Biol. 9, 893-U839. doi:10.1038/ ncb1616
Yang, C. M., Chien, C. S., Yao, C. C., Hsiao, L. D., Huang, Y. C., and Wu, C. B. (2004). Mechanical strain induces collagenase-3 (MMP-13) expression in MC3T3-E1 osteoblastic cells. J. Biol. Chem. 279, 22158-22165. doi:10.1074/jbc.M401343200

Zaman, M. H. (2006). Multiscale modeling of tumor cell migration. Phys. Biol. 851, 117-122.

Zaman, M. H., Matsudaira, P., and Lauffenburger, D. A. (2007). Understanding effects of matrix protease and matrix organization on directional persistence and translational speed in three-dimensional cell migration. Ann. Biomed. Eng. 35, 91-100. doi:10.1007/ s10439-006-9205-6

Zaman, M. H., Trapani, L. M. Siemeski, A., MacKellar, D. Gong, H., Kamm, R. D., et al. (2006). Migration of tumor cells in $3 \mathrm{D}$ matrices is governed by matrix stiffness along with cellmatrix adhesion and proteolysis. Proc. Natl. Acad. Sci. U.S.A. 103, 13897-13897. doi:10.1073/ pnas.0604460103

Zhang, Y. H., Nojima, S., Nakayama, H., Jin, Y. L., and Enza, H. (2003). Characteristics of normal stromal components and their correlation with cancer occurrence in human prostate. Oncol. Rep. 10, 207-211.

Conflict of Interest Statement: The authors declare that the research was conducted in the absence of any commercial or financial relationships that could be construed as a potential conflict of interest.

Received: 07 February 2013; paper pending published: 18 March 2013; accepted: 21 May 2013; published online: 11 June 2013.

Citation: Katira P, Bonnecaze RT and Zaman MH (2013) Modeling the mechanics of cancer: effect of changes in cellular and extra-cellular mechanical properties. Front. Oncol. 3:145. doi: 10.3389/fonc. 2013.00145

This article was submitted to Frontiers in Molecular and Cellular Oncology, a specialty of Frontiers in Oncology.

Copyright $\odot 2013$ Katira, Bonnecaze and Zaman. This is an open-access article distributed under the terms of the Creative Commons Attribution License, which permits use, distribution and reproduction in other forums, provided the original authors and source are credited and subject to any copyright notices concerning any third-party graphics etc. 